\title{
Patient access to the Internet
}

\section{A survey of availability of the Internet to patients in North Manchester 1998-2000}

\author{
J Miles, SP Hanley, A Williams, JM Couriel, V Nathoo, J Roberts and L Hopkinson
}

\section{Jon Miles}

Consultant

\section{Simon Hanley}

Consultant

\section{Andrew Williams}

House Officer

North Manchester General Hospital, Delaunays Road, Crumpsall, Manchester M8 5RB, UK

\section{Jon Couriel}

Consultant

\section{Booth Hall Children's} Hospital, Charlestown Road, Blackley,

Manchester M9 7AA, UK

\section{Vijay Nathoo}

General Practitioner

Five Oaks Medical Centre, Oak House, 47 Graham

Street, Baswick,

Manchester M11 3BB, UK

\section{June Roberts}

Practice Nurse

Langworthy Road Medical Centre, 250 Langworthy Road, Salford M6 5WW, UK

\section{Linda Hopkinson}

Respiratory Nurse

Hope Hospital, Stott Lane, Salford M6 8HD, UK

Correspondence to: Dr J Miles

JMHOME@compuserve. com

Date received: $11 / 07 / 00$

Date accepted: 04/08/00

Prim. Care Respir. $J$ 2000;9(2):32-3

\section{ABSTRACT}

Aim: To discern the availability of the Internet to patients attending clinics and surgeries in North Manchester General Hospital, UK.

Method: A multidisciplinary group designed a questionnaire to be distributed to patients attending the authors' clinics between each October and November for five years.

Results: The data from 1998 and 1999 are presented here. Three quarters of patients surveyed were unable to access the Internet and a significant number had no future plans to do so.

Discussion: If access rates remain low over the next three to four years it is likely that the authors will continue to focus on providing patient information via the Internet at out-patient clinics.

\section{INTRODUCTION}

It is estimated that 332 million people are users of the Internet ${ }^{1}$ and a recent survey has revealed an estimated $33 \%$ of US adults have tried to access health-related sites on the world wide web. ${ }^{2}$ The situation in the UK is less well known, although $15 \%$ of general practitioner (GP) surgeries ${ }^{3}$ are on-line and the Government has endorsed patient access to the Internet by the promotion of NHSNet.

In May 1998, whilst attending the American Thoracic Society Meeting, one of the authors ( $\mathrm{SH}$ ) took advantage of an opportunity to set up a Chest Directorate Website for North Manchester General Hospital. At a subsequent departmental meeting it was discussed whether the website should contain information of use to patients attending our and neighbouring hospitals, or whether it should be predominantly for use by other health professionals. In order to organise the site, it was decided to survey the local population.

\section{METHODS}

A multidisciplinary group with representatives from primary and secondary care, looking after both adults and children, agreed a questionnaire design. The aim was to discern the availability of the Internet to patients attending our clinics and surgeries, and then the attitudes of these subjects to it. Patients will be surveyed during the months of October and November for a five-year period from 1998, the data for 1998 and 1999 are presented here. Data were collected by approaching consecutive attenders at clinics undertaken by the authors. Unfortunately between 1998 and 1999 a colleague at Hope Hospital moved jobs and the data for this year were only collected at four sites. All data were analysed using descriptive statistics (Excel 97) and the study received approval from the ethics committee at North Manchester.

\section{RESULTS}

Data for 202 patients surveyed in 1998 are shown in Table 1 whilst those for 165 patients surveyed in 1999 are shown in Table 2.

There were no significant differences in either the ages or sex of the samples chosen during the two stages of the study (mean age 1998: $37.2 \mathrm{yr}$ vs mean age 1999: $43.5 \mathrm{yr}$; $58 \%$ F 1998 vs $52.3 \%$ F 1999).

Only one in four patients attending our clinics had access to the Internet, either at home or at work, and this figure has remained constant over the last two years. North Manchester is an area of high deprivation with one in three of our nearby houses occupied by a family member on income support.

In $1998,74 \%$ of people with the ability to access the Internet had done so for the purpose of obtaining medical information. A hospital website containing medical information would be found useful by $87 \%$ of responders. By contrast in the 1999 survey, only $19.5 \%$ of patients with access used the Internet for obtaining medical information. However, $86 \%$ still felt that a hospital website would be useful.

There was a trend, in both years, for patients with future plans to access the Internet for medical information to be younger (1998: $25.6 \mathrm{yr}$ vs $44.2 \mathrm{yr}$; 1999: $29.2 \mathrm{yr}$ vs $49.3 \mathrm{yr}$ )

Table 1: Internet access in $1998(n=202)$

\begin{tabular}{lll} 
Access & With access (25\%) & Without access (75\%) \\
\hline Home & $35 \%$ & $\mathrm{n} / \mathrm{a}$ \\
Work & $52 \%$ & $\mathrm{n} / \mathrm{a}$ \\
Both & $13 \%$ & $\mathrm{n} / \mathrm{a}$ \\
Age (mean yr) & 29.1 & 40.1 \\
Sex & $55.6 \% \mathrm{~F}$ & $59 \% \mathrm{~F}$ \\
& $44.4 \% \mathrm{M}$ & $41 \% \mathrm{M}$ \\
Planning to use & & \\
in future & $81.5 \%$ & $15.5 \%$ \\
\end{tabular}

Table 2: Internet access in $1999(n=168)$

\begin{tabular}{lll} 
Access & With access (26\%) & Without access (74\%) \\
\hline Home & $61.2 \%$ & $\mathrm{n} / \mathrm{a}$ \\
Work & $10.5 \%$ & $\mathrm{n} / \mathrm{a}$ \\
Both & $28.3 \%$ & $\mathrm{n} / \mathrm{a}$ \\
Age (mean yr) & 31.5 & 48.0 \\
Sex & $49 \% \mathrm{~F}$ & $47 \% \mathrm{~F}$ \\
& $51 \% \mathrm{M}$ & $53 \% \mathrm{M}$ \\
Planning to use & & \\
in future & $69.2 \%$ & $26.6 \%$ \\
\end{tabular}




\section{DISCUSSION}

Despite a concerted effort on the part of politicians and suppliers, the majority of patients surveyed in clinic settings in both primary and secondary care (adult and paediatric clinics) were unable to access the Internet and a significant number have no future plans to do so. These data have potentially important clinical implications, not only for our directorate, but also for the organisers of healthcare in our area. We have a number of options as a directorate to consider in terms of our website. It is still possible for us to develop medical information, but we must also provide the means by which our patients can access it. With the large number of health-related sites available it appears more sensible to identify sites most useful for our patients and provide a patient information service, rather than develop our own. To this end $\mathrm{SH}$ and colleagues have developed a patient information suite in the adult out-patient clinic at North

Manchester General Hospital. ${ }^{4}$ At the time of writing this is in its early stages and has yet to be evaluated formally by the users.

In 1998, the majority of patients accessing the Internet did so at work, whilst in 1999, it was more likely for patients to have access at home. Home computers are continuing to fall in price and most available have the means to get on-line as part of the initial purchase. In addition it is now possible to use television as means of access to the Internet. It is anticipated that Internet access will as freely available at home as at work over the next few years.

It is assumed that Internet users will continue to increase over the coming years, but it is also possible that pockets of the UK will continue to lag behind the national average. It is not unreasonable to postulate that Internet use may be lower in areas of greater social deprivation. North Manchester is potentially such an area. In order to monitor local Internet use by our patients we intend to undertake our survey over the next 3-4 years. Should access rates remain low it is likely that our focus will continue to be on the provision of patient information via the Internet at outpatient clinics. With the advent of on-line communication between primary and secondary care centres the potential exists for the use of such information suites by primary care staff and patients.

\section{References}

1. Internet Access Survey. Mori 2000

2. Internet Access Survey. 2000 Feb. Available from URL: http://www.cyberdialogue.com

3. NOP Research Group. Internet will be a significant information source for GPs in the new millennium - Survey Findings [monograph on-line] 1998 Aug 6: [1 screen] Available from URL: http://www.nop.co.uk

4. Hutchinson M. Does the Internet give your patients cyberchondria? Hospital Doctor 2000 Jun 15;28-9, 32-3 